\title{
Contributions
}

Ye (George) Jia*

\section{Financing High-tech Start-ups: Moral Hazard, Information Asymmetry and the Reallocation of Control Rights}

\begin{abstract}
Recent data suggest that venture capital investments concentrate in the high-tech sector only in those countries where banks are not allowed to offer equity financing. To explain this fact, I develop a simple principal-agent model of start-up financing with both private information and hidden actions in which the equity investor can vary the level of control over the firm and the debt investor cannot. The model shows that when three commonly documented characteristics of the high-tech industry coexist, namely: (i) a high degree of information asymmetry, (ii) a high level of uncertainty about returns, and (iii) a large amount of R\&D investments preceding production, then the ability to reallocate control rights that are contingent on performance becomes the key. Unlike debt contracts, equity contracts specify detailed provisions regarding the allocation of control rights. Thus, venture capitalists as equity holders have a clear advantage in financing young high-tech firms in places where banks are not allowed to offer equity contracts; in countries with no such restriction, they no longer have such an advantage. This result helps explain why most European governments' efforts in promoting venture capital activities failed to attract such investments in the high-tech sector.
\end{abstract}

Keywords: start-up, venture capital, control rights, moral hazard, information asymmetry

DOI 10.1515/bejeap-2013-0190

\section{Introduction}

The importance of U.S. venture capitalists' role in fostering innovative high-tech firms over the past 40 years has been well documented. Meanwhile, the

*Corresponding author: Ye (George) Jia, Department of Economics, University of Prince Edward Island, 550 University Ave, Charlottetown PE, Canada C1A4P3, E-mail: yjia@upei.ca 
high-tech sector continues to receive disproportionately high levels of investment from venture capitalists; in fact, almost $90 \%$ of U.S. venture capital investments are in that sector. Apple Computers, Cisco Systems, Google, Microsoft, and SUN are just a few of the most famous U.S. companies to get funding from venture capitalists while they were young. In hopes that venture capital would lead to the same success in Europe's high-tech sector, policymakers there led a drastic expansion of public programs that encouraged the formation of venture capital in the 1990s (Tejada 2003; Baygan 2003a,2003b; Baygan and Freudenberg 2000). However, despite European governments' efforts, only a few European countries have achieved levels (measured as a percentage of GDP) of venture capital investments in their high-tech sector that are comparable to that in the United States (for details, see Figure 1). To put it simply, although there has been a rapid growth of venture capital investments in the region, the majority of them did not end up in the high-tech sector.

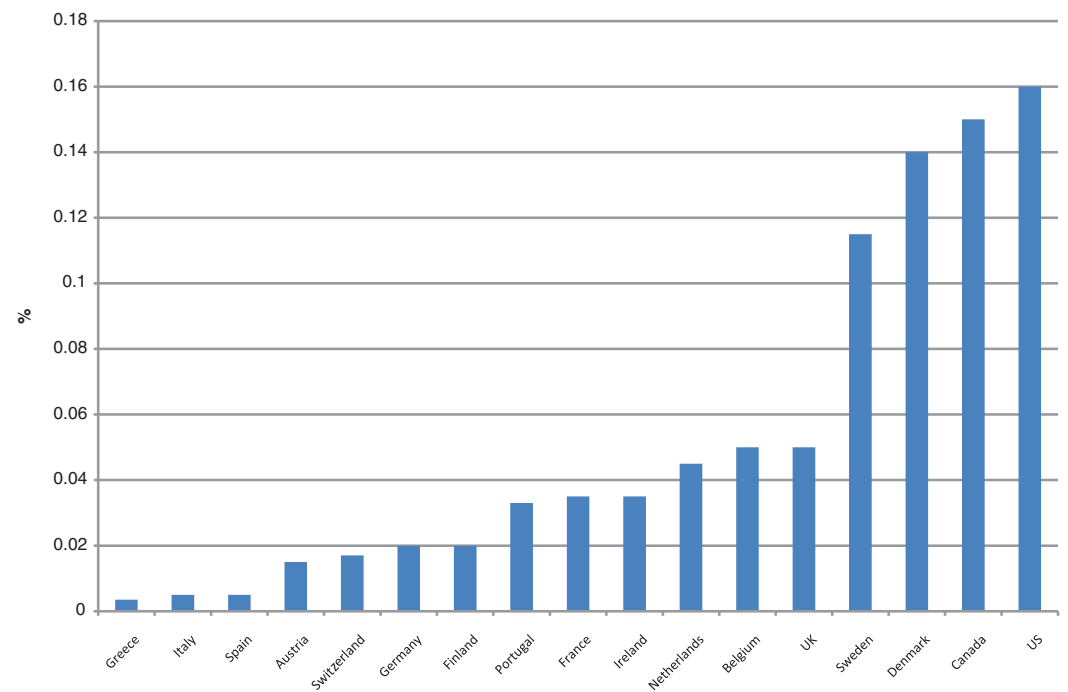

Figure 1: Venture capital high-tech investments as percentage of GDP, 2004-2005

The purpose of this paper is modest. I offer a novel explanation for why venture capital is not as important for high-tech startups in many European countries as it is in North America. In particular, North American banks, unlike their counterparts in many European countries, are not legally allowed to make use of equity contracts - which is better suited for high-tech start-up financing - when investing in new ventures. Policy-makers and researchers often believe that venture capital is better suited for the high-tech sector because venture 
capitalists' expertise in monitoring and screening, plus their ability to take equity positions in venture firms, is useful in solving three problems commonly associated with high-tech investments (Carpenter and Petersen 2002; Hall 2002; Himmelberg and Petersen 1994): first, the returns to such investments are skewed and highly uncertain, because $R \& D$ projects usually have a low probability of financial success. Second, a high level of information asymmetry is likely to exist between firms and potential investors, such that managers have much better information than outsiders about the prospects of the firm's investments. Third, high-tech investments often have limited collateral value, because the R\&D specific investments have little value in the event of failure.

However, there is nothing preventing banks from doing the same type or level of monitoring as venture capitalists do, at least from a legal stand point. Even if banks lack the expertise to perform these tasks, experts could be hired to perform them, as long as it is profitable. In fact, most major commercial banks in Canada have subsidiaries created to provide equity financing to young high-tech firms (Groupe Secor Inc. 1998). ${ }^{1}$ Furthermore, banks can write contingent contracts or impose protective covenants such that the interest rates are based on a firm's performance. In theory, this would allow them to share the upside profit. What, then, is so special about equity financing offered by venture capital firms? Control rights come with partial ownership, ${ }^{2}$ and more importantly, voting rights, cash flow rights, and the ability to allocate and negotiate these rights contingents on the firm's performances.

It is well known that the typical venture capital contracts specify detailed provisions on the allocation of control rights (Bascha and Walz 2001), and venture capital investors usually hold disproportional control over the firm. Even if the venture capital firm holds only a small share of the common stock, it still maintains effective control over the board, either directly through reserved seats or through a disproportionate share of votes. On the other hand, the typical debt contracts offered by banks have no such control right provisions. As argued by Gompers and Lerner (2004), banks in the United States cannot undertake the same type of contracts that venture capitalists do, because regulations limit banks' ability to hold shares in non-financial firms, and so they cannot freely do equity financing. ${ }^{3}$

1 This is a special case within the group of Denmark, Sweden, Canada, and United States. In the other three countries, even the subsidiaries of commercial banks cannot freely offer equity financing, at least not until early 2000.

2 Mainly through the use of convertible securities by venture capital firms in the United States. 3 After the Gramm-Leach-Bliley Act was signed into law in 1999, U.S. banks were permitted to take equity in commercial firms through their merchant banking subsidiaries. Long-term control of commercial firms by a bank, however, is still restricted (Krainer 2000). 
It turns out that these restrictive regulations only exist in a few developed countries, namely Denmark, Sweden, Canada, and the United States, which all have disproportionately high levels of venture capital investment concentrated in their high-tech industries compared to other developed nations (see Figure 1 for details).

In order to illustrate the importance of reallocation of control rights contingent on performance in the high-tech sector, I develop a principal-agent model of start-up financing with information asymmetry, moral hazard, and R\&D investments. In particular, the information asymmetry is captured by the setup in which the entrepreneur learns the true "type" of the project after R\&D investments are made while the investors only get a signal. In addition, the entrepreneur may choose to deviate and enjoy private benefits from the investments at any point. The existence of this moral hazard problem makes it harder to solve the information asymmetry problem by just varying payoffs to the entrepreneur and/or investment levels, because the private benefits from deviating do not depend on the prospects of the project, but on the actual investment level. One crucial assumption is that the moral hazard problem can be directly tackled by varying the level of control over the firm, as is the case for a typical venture capital contract; when a portfolio firm is not performing well, the venture capital firm monitors more intensively and gains more or complete control of the firm. When these three commonly documented characteristics of the high-tech firm coexist, namely: (i) a high degree of information asymmetry, (ii) a high level of uncertainty about returns, and (iii) a large amount of R\&D investments preceding production, then the ability of lenders to vary the level of control contingent on performance becomes the key.

The model is used to illustrate one important point: In the presence of a information asymmetry problem, it is crucial for the financier to directly tackle the moral hazard problem rather than to use the limited set of tools available to debtors like varying funding levels or interest rates. There is other industries associated with great uncertainty about their returns as well, but usually don't have the same level of information asymmetry between the entrepreneurs and their financiers, for instance, the mining industry. The result here provides support for the view that ownership-equity type financing is better suited to funding young high-tech firms, although not necessarily by a venture capitalist. Thus, in countries where equity financing from commercial banks is restricted, venture capital firms have a clear advantage in investing in high-tech firms. In countries without such regulations, venture capital firms no longer have this advantage and are less likely to invest in the high-tech sector. Indeed, venture capital investments in those four countries with strict regulations are more heavily concentrated in the high-tech sector compared to others. 
The prediction of the model is consistent with Kaplan and Strömberg (2003)'s empirical findings, who documented that the typical venture capital contract is structured so that the venture capitalist obtains more control rights if the firm performs relatively poorly, and the entrepreneur retains more control rights otherwise.

Many studies have tried to explain why venture capital is special. Ueda (2004) posit a model in which the venture capitalist has an advantage in evaluating a project, but can "steal" it from an entrepreneur. The prediction that projects with higher returns, higher risks and lower collateral values are financed through a venture capitalist is similar to this paper's, but the intuition is different. Holmstrom and Tirole (1997) develop a model of financial intermediaries that can monitor an entrepreneur's effort, and they also show that entrepreneurs finance through equity if they are short of collateral. Bottazzi, Da Rin, and Hellmann (2008) argued that the non-financial services offered by venture capital are important to the success of portfolio companies. Hsu (2004) also showed that these non-financial services are important, such that offers made by venture capitalists with high reputation are more likely to be accepted even on average they acquire start-up equity at 10-14\% discount. Black and Gilson (1998) argued that these non-financial services offered by venture capital loses its efficiency as a portfolio company matures. Thus, an effective exit strategy for the the financiers is important. That is why an active stock market for IPO exit of the venture capitalist is important for a successful venture capital industry. Such view is shared by Baygan and Freudenberg (2000) and others. These papers offer little insights regarding the cross-country differences in sectoral allocation of venture capital investments. For instance, several countries with less active stock markets have a comparable total and per-capita levels of venture capital investment as the United States, but all have much lower levels of high-tech venture capital investments.

Several other papers deal with the allocation of control rights in venture capital financing. Cornelli and Yosha (2003) argued that venture capital firms use staging and convertible securities with control rights clause together as a solution to the conflict of interest between the venture capital firms and the entrepreneur, much as in this paper. Berglöf (1994) claimed that state-contingent allocation of control rights through convertible securities allocates control to the party that has the higher outside option. Bascha and Walz (2001) showed that state-contingent control rights help implement the first best decision regarding IPO. Schmidt (2003) argued that usage of convertible debt can implement efficient effort levels from both the venture capital and the entrepreneur. Unlike these papers, I show the importance of the investor's ability to vary levels of control. I focused on this effect rather than the two-sided bargaining process between entrepreneurs and investors over payoffs or control rights, and 
the final IPO exit decisions. In particular, I show that having controlling ownership becomes more important as the level of uncertainty about returns increases, and when information asymmetry and moral hazard problems worsen.

The rest of the paper is organized as follows. Section summarizes the facts about relevant banking regulations and venture capital investment patterns across countries; Section 3 describes the model. A characterization of the optimal contracts offered by debt and equity investors is presented in Section 4 and Section 5 offers a conclusion.

\section{Banking regulations and venture capital investments across countries}

Regulations on commercial banks holding equities in non-financial firms for a sample of 17 European and North American countries are presented here. Several are very restrictive: Denmark's commercial banks may not hold permanent, decisive participation in a non-financial firm; Canadian banks can hold at most 10\% of total shares of a non-financial firm ${ }^{4}$; Portugal's banks may hold no more than $25 \%$ of voting power in non-financial firms that they invest in; Sweden's banks can only hold up to 5\%; and U.S. banks are not allowed to offer equity financing, unless the firm in question is small and in financial distress. Even in that situation, banks are still prohibited from getting involved with the business decision-making. All other countries' regulations in the sample closely follow the EC banking ACT II, which allows banks to take equity stakes in non-financial firms. Only two among these countries enforce extra restrictions: In the Netherlands, banks are required to get permission from the government to hold greater than $25 \%$ of shares in a nonfinancial firm, and in the UK, banks are required to remove the equity holdings from their assets when reporting banking risks, if the equity holding is greater than $15 \%$ of the firm's outstanding shares.

The statistics on venture capital investments are taken from publications by the national venture capital association 2006, Canada's venture capital and private equity association 2006, and the European venture capital association 2006. ${ }^{5}$ Figure 2 shows the total flow of venture capital investments in 2004-2005 as a fraction of GDP for all sample countries. Although the U.S.' venture capital industry

\footnotetext{
4 As mentioned before, they are allowed to set up subsidiaries that provide equity financing. 5 The total venture capital investments reported by the European venture capital association include buy-outs funds and other very late-stage private equity investments, unlike its North American counterparts. To avoid any confusion, I will use the term venture capital in this article to refer to early to expansion stage investments only, excluding buy-outs. A similar argument has been made by
} 
is the most mature, other countries are catching up. Canada's, Sweden's and UK's total investment levels as share of GDP have already surpassed that of the United States; the same holds on a per-capita basis. Figure 3 presents high-tech as a fraction of total venture capital investments levels for the same group of countries. Greece's venture capital industry is particular high in this category simply because Greek venture capital firms could only invest in the high-tech sector by law, and as a result, the total venture capital investment level is the lowest. Ireland's number is high also because of regulatory restrictions. Figure 1 reports the venture capital investments in the high-tech sector as a fraction of GDP for these countries. The group of four countries that put tight restrictions on equity financing offered by banks, namely, Canada, Denmark, Sweden, and the United States, clearly stands out from the rest. Sweden's share, which is the lowest among these four countries, is still more than twice as much that of Belgium, which has the fifth highest share among all sample countries. The United States has almost four times as much. Lastly, Figure 4 reports venture capital investments in the high-tech sector as a share of total R\&D spending, which can be viewed as an imperfect measure of venture capital investments' share of the high-tech sector. Once again, the group of countries with strict regulations stands out from the others, including Portugal.

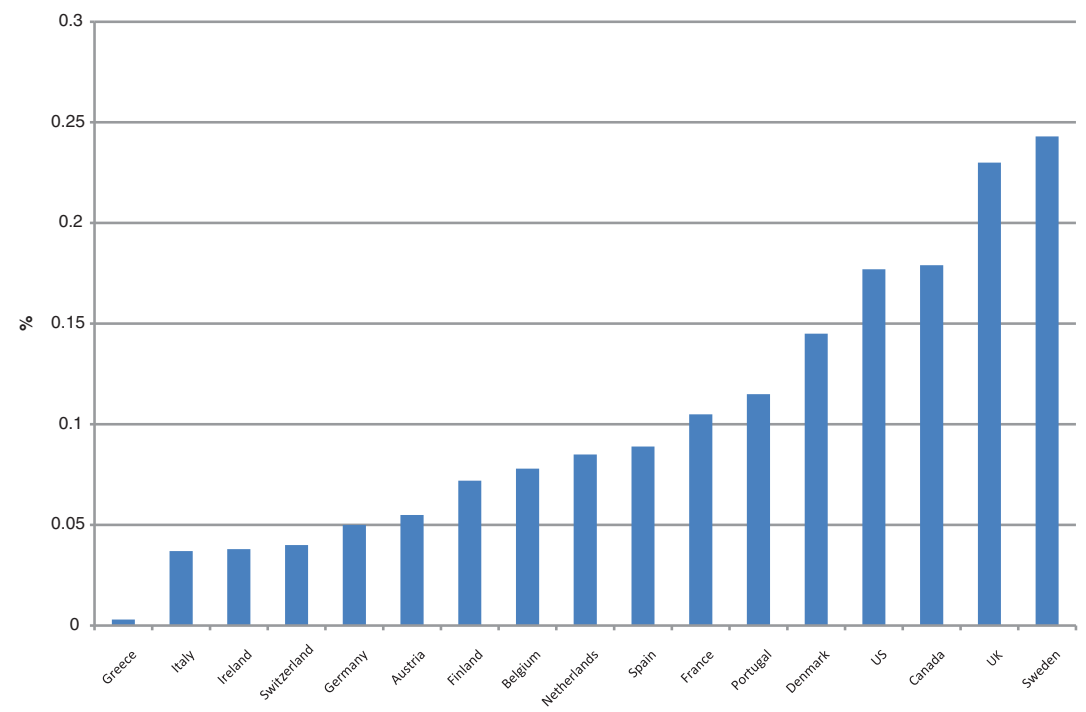

Figure 2: Venture capital investments as percentage of GDP, 2004-2005

Tyabji and Sathe (2011). Following the definition of NVCA, venture capital investment = Startup/Seed +Early + Expansion, we transform the data from EVCA in the following way: venture capital investment $=$ Private Equity investment - buyout - replacement capital. 


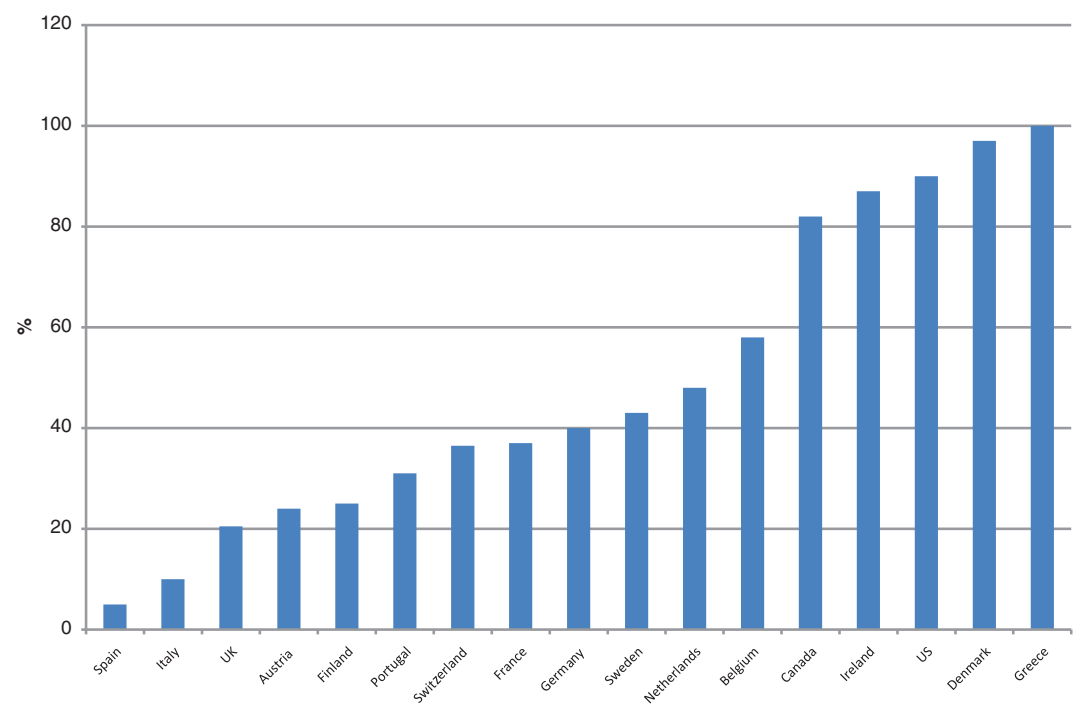

Figure 3: Percentage of venture capital investments goes into high-tech sector, 2004-2005

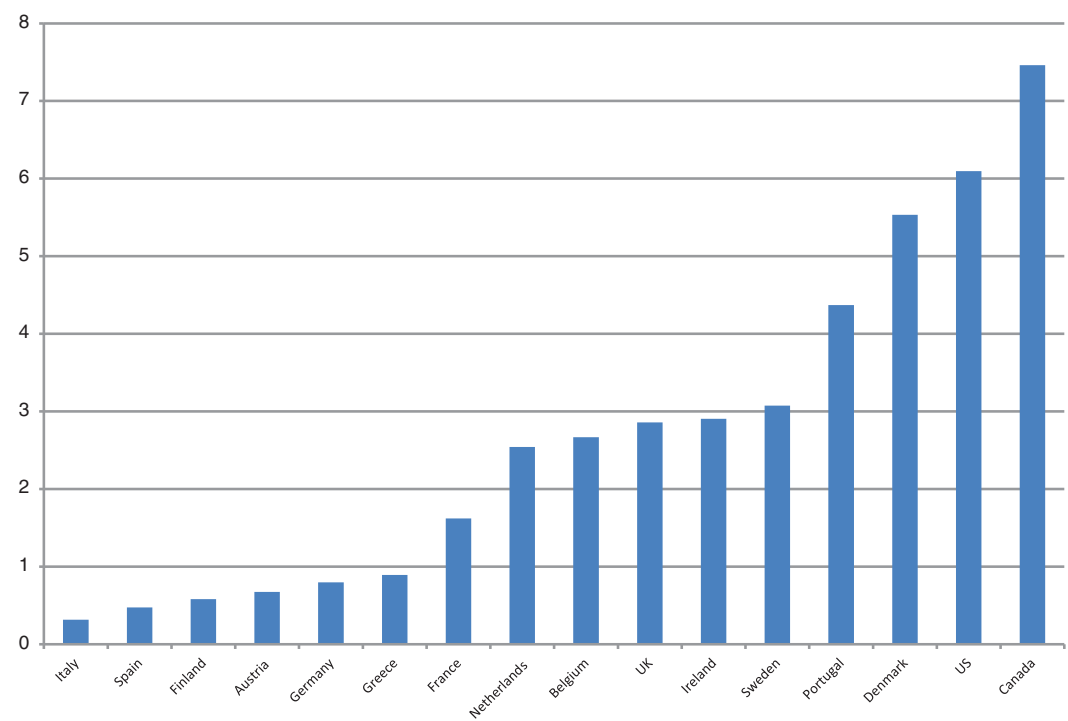

Figure 4: Venture capital high-tech investments as percentage of R\&D expenditure, 2004-2005

Based on these statistics, we can conclude that in this sample of countries, those with stricter restrictions on commercial banks holding controlling equity in nonfinancial firms had disproportionately high levels of venture capital investment in their high-tech sectors. This suggests that venture capital firms in these 
countries do enjoy certain advantages in investing in the high-tech sector. In the next section, I construct a simple model to explain why equity financing with ownership is more suitable for high-tech firms.

\section{Model}

A project involves a risk-neutral entrepreneur/manager with an idea, and a riskneutral investor, either a venture capital firm or a bank. The entrepreneur (manager) does not have any wealth, so she needs external financing to start the project. Only the venture capital firm and bank can commit to contractual arrangements, although they have all the bargaining power in designing the contract.

The project takes three periods to mature: an R\&D period, a production period, and a payout period. In the first period, the contract is signed and then is followed by $R \& D$ investments. In the second period, the entrepreneur first decides whether to leave the contract arrangement, and then production investment is made. In the final period, investment returns are realized, and claims are settled. Timing of the model is illustrated in Figure 5.

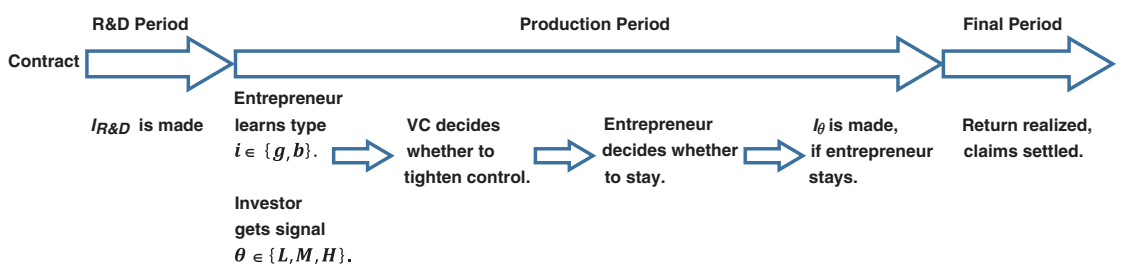

Figure 5: Timing

Each entrepreneur only has one project or idea. It costs a fixed amount of investment $I_{\text {R\&D }}$ to undertake the research and development in period 1 . Production investment $I$ is chosen from the interval $[0,1]$ in period 2. In period 3, the investment generates a verifiable financial return equaling 0 (failure) ${ }^{6}$ or $I \times R$ (success). Each project is one of two types, good or bad, which differ in

6 This implies that investments have no collateral value; such assumption does remove certain advantages of debt contracts, but investments in high-tech sector usually have very low collateral value (Hall 2002; Himmelberg and Petersen 1994). 
their probability of success. ${ }^{7} \eta$ fraction of the projects are of good type and the rest are of bad type. This probability is public knowledge.

\begin{tabular}{lll}
\hline Type & Good & Bad \\
\hline Probability of success & $p_{h}$ & $p_{l}$ \\
Probability of being type $i$ & $\eta$ & $1-\eta$ \\
\hline
\end{tabular}

I assume that

$$
\Delta p=p_{h}-p_{l}>0
$$

and denote the unconditional probability of successes as $\hat{p}=\eta p_{h}+(1-\eta) p_{l}$. Furthermore, the rate of return on investment capital is assumed to be 0 for simplicity, and only good type projects are economically viable:

Assumption $1 p_{h} R-\frac{I_{R \& D}}{\eta}>1>p_{l} R$

The reason that $\frac{I_{\mathrm{R \& D}}}{\eta}$ is on the left side instead of $I_{\mathrm{R \& D}}$ is because there is no way of separating the bad projects from the good ones in the first period. Thus, $I_{\mathrm{R} \& \mathrm{D}}$ is necessary for all projects, even if none of the bad projects continue past the second period. In other words, $I_{\mathrm{R} \& \mathrm{D}}$ for bad projects is a part of the required upfront cost; then for the good projects to be economically viable, their return has to cover not only their share of the R\&D investments, but also the bad ones' share.

There is information asymmetry between the entrepreneur and her financier. At the time when a contract is signed, neither the entrepreneur nor her financier knows the true type of the project. The entrepreneur learns her project's true type at the second period, with certainty. On the other hand, only a fraction $\lambda$ projects' true type is revealed to their financiers. I will formulate the information obtained by investors in period 2 as a signal, where $\theta$ is drawn from the set $\{H, M, L\}$, such that:

$$
\begin{gathered}
\operatorname{Prob}\{i=\operatorname{good} \mid \theta=H\}=\operatorname{Prob}\{i=\operatorname{bad} \mid \theta=L\}=1 \\
\operatorname{Prob}\{i=\operatorname{good} \mid \theta=M\}=1-\operatorname{Prob}\{i=\operatorname{bad} \mid \theta=M\}=\eta
\end{gathered}
$$

7 An alternative way of modeling this is to assume that projects differ in their rates of returns (i.e., $R_{H}>R_{L}$ ) but have the same probability of success. Since all parties are risk-neutral, the model's qualitative predications should not depend on which setup I choose. 
Thus, from the viewpoint of financiers, projects with signal $H$ are of the good type, while those with signal $L$ are of the bad type. They are not sure about the true type for projects with signal $M$, but know that with probability $\eta$, they are of the good type.

In the absence of proper incentives or monitoring, the entrepreneur may choose to deviate and use resources for a private benefit, such action lead to project failure in the payoff period. The private benefit from this action is equal to a share $\gamma$ of the investment $I$ in that period, where $\gamma \in(0,1)$. In addition, the entrepreneur also has an outside option: an reservation utility per period, denoted $\varpi$, which represents the sum of the outside wage and disutility of effort devoted to the project, all measured in monetary term. I assume that,

\section{Assumption $22 \varpi>\gamma \times 1>\varpi$}

such that the private benefits derived by deviating from a fully funded project are higher than the payoff of working somewhere else for one period, so the entrepreneur has an incentive to continue a well-funded bad project. On the other hand, it's not worthwhile to participate in a project just for the sake of enjoying the private benefits.

This hidden action needs not solely to represent the situation in which the entrepreneur uses all resources for personal benefits. It is to capture two types of agency costs that commonly exist with entrepreneurial firms (Gompers and Lerner 2004). First, entrepreneurs might want to invest in research or projects that have high personal returns but not high monetary payoffs to their financiers. Take the example of a biotechnology firm: the manager may choose to invest in research that brings greater recognition in the scientific community but provides less financial returns. Second, the entrepreneur might possess private information and choose to continue investing in a project with lower expected payoffs. For example, managers might learn the demand for a new product is low, but want to keep the company going because they have private benefits from managing their own firms.

I assume that the main difference between the two kinds of financier is that a venture capitalist as an equity holder can eliminate the moral hazard problem by more intensely monitoring and placing tighter control over a firm at a fixed cost, $c$, so that the entrepreneur cannot extract private benefits from the project. ${ }^{8}$ The bank as the debt holder, on the other hand, cannot. Suppose a venture firm's performance is in question, but not terrible enough that it clearly should

8 This is similar to Holmstrom and Tirole (1997)'s set up. However, the private benefits of deviating do not depend on the investment level in their model. 
be terminated. In this situation, it is more likely that the entrepreneur is going to use company resources for private benefits, especially if the entrepreneur secretly knows that the outlook for the firm is bad. To solve this problem, an venture capital firm may monitor the management more intensely or even take over the firm. More importantly, venture capital firms can directly intervene in the management and take away key control rights if they deem it necessary. Debt investors, on the other hand, could monitor the firm more intensely, but lack the ability to directly intervene. They have to use other means to solve the problem: raise interest rates and lower or stop further funding. ${ }^{9}$

\section{Optimal contracts}

In this section, I derive the optimal contracts that the bank and the venture capital firm offers. ${ }^{10}$ These contacts are written in the form of a take it or leave it offer to the entrepreneur. I assume that once a contract is signed then it is too costly for the entrepreneur to void it and seeks another offer from other financiers.

\subsection{Bank contract}

A contract can be characterized by $\Psi=\left\{I_{M}, I_{H}, y_{M}, y_{H}\right\}$ where $y_{\theta}$ is the final payoff to the entrepreneur upon project success and $I_{\theta}$ is the investment level at the production period. The bank can alter investments and payoffs contingent on signals $\theta \in\{L, M, H\}$ that the financier receives after the R\&D period. In principle, $I_{\mathrm{R} \& \mathrm{D}}$ and $\left\{y_{L}, I_{L}\right\}$ should also be specified in the contract, but the former cannot be chosen, and the latter are trivially set to $\{0,0\}$, since bad projects are not economically viable; thus, they are omitted from the contract specification.

Although a typical loan contract states interest rates rather than payoffs to the borrower, there is a one-to-one mapping between the two in this model, i.e.: the interest rate could be calculated as $r_{\theta}=\frac{R I_{\theta}-y_{\theta}}{I_{\text {R\&D }}+I_{\theta}}$. To denote the contract in this fashion makes it easier to compare the bank contract to its counterpart offered by the venture capital firm.

Given the model specification, one out of the following two contracts will delivery the most profits to the bank:

9 The other difference between the two, is the ability to request collateral. However, as discussed before, high-tech investments in general have little collateral value.

10 Optimal with respect to the tools that each investor has in designing the contract. 
1. Fund all projects with signal $M$ and $H$ fully, not screening out bad projects with medium signals; or

2. Fund projects with signal $H$ fully and place a credit limit for projects with signal $M$ so that entrepreneurs with bad project will take the outside option.

I will call the first a no credit rationing contract, and the second a credit rationing contract.

\subsubsection{No credit rationing contracts}

The contracting problem in which the bank fully funds all projects with signal $M$ and $H$ without screening is:

$$
\max _{I_{M} \in[0,1], I_{H} \in[0,1], y_{M}, y_{H}} E_{0}(\pi)
$$

subject to:

$$
\begin{gathered}
E_{0}(y) \geq 2 \varpi \\
E_{0}(y) \geq \gamma I_{\mathrm{R} \& \mathrm{D}}+\varpi \\
E_{1}(y \mid \theta, i=G) \geq \varpi \quad \forall \theta \\
E_{1}(y \mid \theta, i=G) \geq \gamma I_{\theta} \quad \forall \theta \\
E_{1}(y \mid \theta=M, i=B) \geq \gamma I_{M}
\end{gathered}
$$

$E_{0}()$ here is the expectation operator, the bank maximizes its expected profits at the time when the contract is signed. Equations [2] and [4] are participation constraints, such that the expected final payoff at the time when the contract is signed, $E_{0}(y)$, is at least as good as the outside option; the same holds in the second period for all entrepreneurs with good type projects. Equations (3, 5, and 6) are the incentive compatibility constraints such that entrepreneurs who should continue to run projects do not deviate and seek private benefits. Such problem is a linear maximization problem with only linear constraints. Here, either eqs [2] or [3] binds with equality depending on which of the following values is higher: $\left\{\varpi, \gamma I_{R \& D}\right\}$. Equation (6) binds with equality, such that $p_{h} y_{M}=\gamma$. The solution to the contract problem is

$$
\Psi^{n c r}=\left\{I_{M}^{n c r}=1, I_{H}^{n c r}=1, y_{M}^{n c r}=\frac{\gamma}{p_{h}}, y_{H}^{n c r}=\frac{\max \left\{\varpi, \gamma I_{\mathrm{R} \& \mathrm{D}}\right\}+(1-(1-\eta) \lambda) \varpi-(1-\lambda) \frac{\gamma}{p_{h}} \hat{p}}{p_{h} \eta \lambda}\right\}
$$


Note that under this contract, all good projects get fully funded. However, since there are $(1-\lambda)$ fraction of projects' type are not revealed to the bank, this much fraction of bad projects also get fully funded, which generate losses. All entrepreneurs with medium signals are paid less than those with high signals in the third period if the project is a success; in other words, they pay a higher interest rate. The expected profit for the bank under this contract is:

$$
\pi^{n c r}=\eta\left(p_{h} R-1\right)+(1-\eta)(1-\lambda)\left(p_{l} R-1\right)-I_{\mathrm{R} \& \mathrm{D}}-[1-\lambda(1-\eta)] \varpi-\max \left\{\varpi, \gamma I_{\mathrm{R} \& \mathrm{D}}\right\}
$$

The first term is the return from good type project, and the second term is the loss from bad projects, the last two terms represent the payoff to the expected entrepreneur.

\subsubsection{Credit rationing contract}

The contract problem when a bank tries to screen out bad projects with medium signal is:

$$
\max _{I_{M} \in[0,1], I_{H} \in[0,1], y_{M}, y_{H}} E_{0}(\pi)
$$

subject to:

$$
\begin{gathered}
E_{0}(y) \geq 2 \varpi \\
E_{0}(y) \geq \gamma I_{\mathrm{R} \& \mathrm{D}}+\varpi \\
E_{1}(y \mid \theta, i=G) \geq \varpi \quad \forall \theta \\
E_{1}(y \mid \theta, i=G) \geq \gamma I_{\theta} \quad \forall \theta \\
E_{1}(y \mid \theta=M, i=B) \leq \varpi \\
\gamma I_{M} \leq \varpi
\end{gathered}
$$

Equations (7-10) are the same as before. Equations [11] and [12] are the incentive compatibility constraints to make sure that entrepreneurs with a bad project and a medium signal do not stay or deviate and enjoy private benefits. Again, either eqs [7] or [8] holds with equality. Equations [11] and [12] both bind, such that $p_{h} y_{M}=\varpi$ and $\gamma I_{M}=\varpi$. The contract is:

$$
\Psi^{c r}=\left\{I_{M}^{c r}=\frac{w}{\gamma}, I_{H}^{c r}=1, y_{M}^{c r}=\frac{w}{p_{h}}, y_{H}^{c r}=\frac{\max \left\{\varpi, \gamma I_{\mathrm{R} \& \mathrm{D}}\right\}}{p_{h} \eta \lambda}+\frac{w\left(1-\frac{1-\lambda}{p_{h}}\right)}{p_{h} \lambda}\right\}
$$


Under this contract, none of the bad type projects get funded in the second period, but a fraction $(1-\lambda)$ of the good projects only gets partially funded. Obviously, their potentials are not fully captured. Expected profit from the credit rationing contract is:

$\pi^{c r}=\eta \lambda\left(p_{h} R-1\right)+\eta(1-\lambda) \frac{\varpi}{\gamma}\left(p_{h} R-1\right)-I_{\mathrm{R \& D}}-[1-(1-\eta)] \varpi-\max \left\{\varpi, \gamma I_{R \& D}\right\}$

The first term is the return from projects with signal $H$, the second term is the return from good type projects with signal $\mathrm{M}$, and the last two terms represent the expected payoff to the entrepreneur. The bank's contract problem can be simply summarized as:

$$
\pi^{\mathrm{Bank}}=\max _{\Psi^{n c r}, \Psi^{c r}}\left\{\pi^{n c r}, \pi^{c r}\right\}
$$

\subsection{Venture capital contract}

A venture capitalist could offer both contracts that the bank offers, because by assumption, a venture capital firm may also alternate the investment level, and the entrepreneur's pay off. Thus, I will just derive the contract in which the venture capital firm alters the level of control to eliminate the possibility of deviation by entrepreneur to enjoy private benefits. By assumption $2, \gamma<2 \varpi$, so a venture capital firm simply places tighter control on a project in period 2 with a medium signal, not those with high signals. In addition, if $I_{R \& D}$ is large enough, a venture capital firm also places tighter control on all projects in the $\mathrm{R} \& \mathrm{D}$ period in order to avoid deviation from the entrepreneur. At first, I will derive the contract in which $I_{\mathrm{R} \& \mathrm{D}}$ is low enough so the venture capital firm does not tighten control in the first period, which happens when $\gamma I_{\mathrm{R} \& \mathrm{D}}<\varpi+c$.

$$
\max _{I_{M} \in[0,1], I_{H} \in[0,1], y_{M}, y_{H}} E_{0}(\pi)
$$

subject to:

$$
\begin{gathered}
E_{0}(y) \geq 2 \varpi \\
E_{0}(y) \geq \gamma I_{\mathrm{R} \& \mathrm{D}}+\varpi \\
E_{1}(y \mid \theta, i=G) \geq \varpi \quad \forall \theta \\
E_{1}(y \mid \theta, i=G) \geq \gamma I_{\theta} \quad \forall \theta \\
E_{1}(y \mid \theta=B, i=B) \leq \varpi
\end{gathered}
$$


Again, eqs [13] and [15] are the participation constraints, eqs [14] and [16] are two incentive compatibility constraints such that entrepreneurs who should continue to run projects do not deviate for the enjoyment of private benefits, and eq. [17] makes sure that entrepreneurs with bad projects and medium signals quit. The moral hazard problem has been taken care of by placing tighter control over the firm for projects with medium signals, so the contract problem has one fewer constraint than the credit rationing contract problem. Thus, if $c$ is zero, then this contract yields at least the same profit as the credit rationing contract does.

Now, consider the case in which R\&D investment is sufficiently high that the venture capital firm will place tighter control in the first period to avoid deviation by the entrepreneur: The only change is that constraint eq. [14] is replaced by $E_{0}(y) \geq 2 \varpi$. Combining these two situations, the full solution to this contract problem can be characterized by:

$$
\Psi^{v c}=\left\{I_{M}=1, I_{H}=1, y_{M}=\frac{\varpi}{p_{h}}, y_{H}=\frac{\Lambda-(1-\eta) \varpi-(1-\lambda) \eta \frac{\varpi}{p_{l}}}{p_{h} \eta \lambda}\right\}
$$

where

$$
\Lambda= \begin{cases}\varpi, & \text { if } \varpi \geq \gamma I_{\mathrm{R} \& \mathrm{D}} \text { or } \gamma I_{\mathrm{R} \& \mathrm{D}}<\varpi+c ; \\ \gamma I_{\mathrm{R} \& \mathrm{D}}, & \text { otherwise; }\end{cases}
$$

Expected profit from this contract is:

$$
\pi^{V C}=\eta\left(p_{h} R-1\right)-I_{\mathrm{R} \mathrm{D}}-(1-\lambda) c-[1-(1-\eta)] \varpi-\min \left\{c, \max \left\{\gamma I_{\mathrm{R} \& \mathrm{D}}, \varpi\right\}\right\}
$$

Here, because the venture capital firm can screen out all bad projects for a fixed $\operatorname{cost} c$, it can fund all good type projects at the efficient size of 1 . Note that, this solution features the characteristic of a typical venture capital contract: When a portfolio firm does well, the manager gets a better payoff and retains more control rights; if it is not doing so well, the manager gets a lower payoff and retains fewer or no control rights; if the firm's performance is especially dreadful, all further funding is cut.

\subsection{Bank contract vs. venture capital contract}

Before comparing these contracts, it is useful to summarize the economic interpretations of variations in some key variables of the model:

- decrease in $\lambda$ (fraction of projects' true type is known to its financiers) represents an increase in the degree of information asymmetry;

- increase in the level of uncertainty about returns is represented by increasing the spread of uncertainty $\Delta p$ while keeping the unconditional probability of success $\hat{p}$ fixed; 
- a higher R\&D investment is simply represented by a higher $I_{\mathrm{R} \& \mathrm{D}}$; and

- the moral hazard problem worsens as $\gamma$ increases.

The table below summarizes the investment level in the production period for each project type with different signals, highlights the main caveats of contracts offered by the bank:

\begin{tabular}{lrrrrr}
\hline Type & \multicolumn{2}{c}{ Good } & & Bad \\
\cline { 2 - 5 } Signal & $\mathbf{H}$ & $\mathbf{M}$ & & $\mathbf{M}$ & $\mathbf{L}$ \\
\hline Fraction & $\eta \lambda$ & $\eta(1-\lambda)$ & & $(1-\eta)(1-\lambda)$ & $(1-\eta) \lambda$ \\
No credit rationing & 1 & 1 & 1 & 0 \\
Credit rationing & 1 & $\frac{w}{\gamma}$ & 0 & 0 \\
Venture capital & 1 & 1 & 0 & 0 \\
\hline
\end{tabular}

Under the no credit rationing contract, all of the good type projects receive full funding; however, some bad projects also receive full funding. On the other hand, the credit rationing contract under-fund some good type projects just to avoid the bad projects with medium signals. To compare the two contracts offered by the bank, I have the following proposition:

Proposition 1 The spread between expected profits of the credit rationing contract and the non-credit rationing contract $\left(\pi^{c r}-\pi^{n c r}\right)$ is:

1. positive when $\hat{p} R-1-(1-\eta) \varpi<+\eta \frac{\varpi}{\gamma}\left(p_{h} R-1\right)$

2. increasing in the spread of uncertainty $\Delta p$ while holding $\hat{p}$ constant; and

3. decreasing (increasing) in $\lambda$ when $\pi^{c r}$ is higher (lower) than $\pi^{n c r}$.

Proof: See Appendix A.

Thus, the credit rationing contract is used by the bank when there is a high degree of information asymmetry and the level of uncertainty about returns is elevated. Note that, in spite of in this relatively simple setup, the tools employed by most commercial banks in solving the agency problem are featured: varying interest rates and the level of further lending contingent on the firm's performance. Even with these tools at hand, banks either have to finance some bad projects under the no credit rationing contract or the investment level is inefficiently low for some good projects under the credit rationing contract.

Proposition 2 The spread between expected profits of the venture capital contract and the bank contract $\left(\pi^{V C}-\pi^{\mathrm{Bank}}\right)$ is: 
1. positive if $c<\min \left\{1-\eta\left(1-p_{l} R+\varpi\right), \eta\left(1-\frac{\varpi}{\gamma}\right)\left(p_{h} R-1\right)\right\}$

2. decreasing in $\lambda$ (fraction of projects' true type are revealed to their financiers) as long as $c<\min \left\{1-\eta\left(1-p_{l} R+\varpi\right), \eta\left(1-\frac{\varpi}{\gamma}\right)\left(p_{h} R-1\right)\right\}$;

3. increasing in the spread of uncertainty $\Delta p$ while keeping $\hat{p}$ constant;

4. increasing in $I_{\mathrm{R} \& \mathrm{D}}$; or

5. increasing in $\gamma$ (the private benefits that entrepreneurs get from deviating).

Proof: See Appendix B.

The first part of the proposition states the sufficient condition under which the venture capital contract generates more profit than the bank contact. The first term inside the min operator is the loss of financing bad projects with medium signal under the no credit rationing contract, and the second term is the loss of potential profits due to insufficient funding of good projects with medium signal under the credit rationing contract. The venture capital contract outperforms the bank contract as long as the cost of eliminating moral hazard $c$ is below the lesser of the two. The second part of proposition states that as the information asymmetry problem worsens, the spread between what the venture capital contract generates and its counterpart generated by the bank contract increases when the venture capital outperforms the bank contract. The rest of the proposition states that the venture capital contract is more profitable when the uncertainty about return rises, R\&D investment increases, or the moral hazard problem worsens. In other words, the proposition shows that when the three characteristics of the high-tech industry coexist, the equity ownership contract is better suited. Mainly due to the interaction between the information asymmetry and the moral hazard problem, the private benefits from the hidden action only depend on the investment level, but not on the prospect for the project itself, which makes it harder to solve the agency problem by simply varying payoff or interest rates and funding levels.

The above proposition shows that the ability of the principal to retain control rights is important for financing young high-tech firms. Thus, the model predicts that in countries where equity financing from commercial banks is restricted, venture capital firms would have an advantage in investing in that sector. In countries where such restrictions are not in place, venture capital firms lose this advantage and have to compete with traditional banks. As a result, venture capital investments should be more concentrated in the high-tech sector where these restrictions exist. Indeed, this prediction is consistent with the empirical facts presented in Section 2. 


\section{Conclusion}

I provide a theory of start-up financing using a simple principal-agent model with both moral hazard and information asymmetry. The model illustrates why it is important for investors of young high-tech firms to be able to reallocate control rights contingent on firm performance, which agrees with observations from real-world venture capital contracts (Kaplan and Strömberg 2003). This result offers an alternative explanation to the observed differences in sectoral allocation of venture capital investments across countries, since in countries where commercial banks are allowed to offer equity financing, venture capital investments do not concentrate on the high-tech sector because they no longer hold certain advantages. There is even evidence suggesting that the investment practices of venture capitalists in Europe are more like traditional banks; compared to their North American counterparts, European venture capital firms (Schwienbacher 2008): (1) hold smaller shares of early-stage investments in their portfolio, (2) use convertible securities less often, and (3) replace management of portfolio firms less frequently.

Lack of financing is often cited as the main reason why the European hightech sector lags behind its U.S. counterparts. This paper argues that most European countries' regulations allowed commercial banks to provide equity financing for young high-tech firms in the region, and even the rapid growth of venture capital funds did not lead to more investments in that sector. Although there is no direct evidence that banks in Europe make equity investments in high-tech start-ups, mainly due to lack of funding source data for the high-tech industry and data on sectoral allocation of equity financing offered by banks, I suspect that funding gap is not the key issue. Clearly, this topic deserves more careful investigation.

Acknowledgment: I am deeply indebted to James MacGee and Igor Livshits. I thank Al Slivinski, Simon Parker and James Sentance for many helpful comments. All errors are mine.

\section{Appendix}

This Appendix contains the proofs of all the results presented in the paper.

\section{A.1 Proof of Proposition 1}

The spread between expected profits for the credit rationing contract and the non-credit rationing contract could be written as: 


$$
\begin{gathered}
\pi^{c r}-\pi^{n c r} \\
=\eta \lambda\left(p_{h} R-1\right)+\eta(1-\lambda) \frac{\varpi}{\gamma}\left(p_{h} R-1\right)-I_{R \& D}-[2-(1-\eta)] \varpi \\
-\eta\left(p_{h} R-1\right)-(1-\eta)(1-\lambda)\left(p_{l} R-1\right)-I_{R \& D}-[2-\lambda(1-\eta)] \varpi \\
=(1-\lambda)\left[1-\hat{p} R+(1-\eta) \varpi+\eta \frac{\varpi}{\gamma}\left(p_{h} R-1\right)\right]
\end{gathered}
$$

1. Increasing in the spread of uncertainty $\Delta p$ while keeping $\hat{p}$ constant:

Proof. I shall prove this by separately showing that the spread between expected profits of the credit rationing contract and the non-credit rationing contract is increasing: first, when increasing $p_{h}$ and lowering $\eta$ while keeping $\hat{p}$ and $p_{l}$ constant; second, when lowering $p_{l}$ and increasing $\eta$ while holding $\hat{p}$ and $p_{h}$ constant; third, when lowering $p_{l}$ and increasing $p_{h}$ while holding $\hat{p}$ and $\eta$ constant. Any other way of increasing the spread of uncertainty $\Delta p$ would just be a linear combination of these three types of changes.

(a) the term $p_{h}$ can be expressed in terms of $\eta, p_{l}$ and $\hat{p}$ in the following way:

$$
p_{h}=\frac{\hat{p}-(1-\eta) p_{l}}{\eta}
$$

substitute this into eq. [18] for $p_{h}$, we have:

$$
\pi^{c r}-\pi^{n c r}=(1-\lambda)\left\{1-\hat{p} R+(1-\eta) \varpi+\frac{\varpi}{\gamma}\left[\left(\hat{p}-p_{l}\right) R-\eta\left(1-p_{l} R\right)\right]\right\}
$$

The partial derivative $\frac{\partial\left(\pi^{c r}-\pi^{n c r}\right)}{\partial \eta}=-\varpi-\left(1-p_{l} R\right)$ is negative. Thus, while I increase $p_{h}$, and lower $\eta$, while holding $p_{l}$ and $\hat{p}$ constant, $\pi^{c r}-\pi^{n c r}$ is increasing.

(b) From eq. [18], we can derive the partial derivative $\frac{\partial\left(\pi^{c r}-\pi^{n c r}\right)}{\partial \eta}=$ $\left(p_{h} R-1\right) \frac{\varpi}{\gamma}-\varpi$. From the assumption that $\left(p_{h} R-1\right)>2 \varpi$ and $\gamma<2 \varpi$, this partial derivative is positive. It means that when I increase $\eta$, and lower $p_{l}$, while holding $p_{h}$ and $\hat{p}$ constant, $\pi^{c r}-\pi^{n c r}$ increases as a result.

(c) Taken from eq. [18], $\pi^{c r}-\pi^{n c r}$ is increasing in $p_{h}$ when holding $\eta$ and $\hat{p}$ constant.

Combining the above three arguments, we can conclude that $\pi^{c r}-\pi^{n c r}$ is increasing in the spread of uncertainty $\Delta p$ while keeping $\hat{p}$ constant.

2. Decreasing(increasing) in $\lambda$ when $\pi^{c r}$ is higher(lower) than $\pi^{n c r}$. 
Proof. We know that $\pi^{c r}-\pi^{n c r}=(1-\lambda) \times\left[1-\hat{p} R+(1-\eta) \varpi+\eta \frac{\varpi}{\gamma}\left(p_{h} R-1\right)\right]$. If the second term is positive, then $\pi^{c r}-\pi^{n c r}$ is decreasing in $\lambda$ as $(1-\lambda)$ is decreasing in $\lambda$. Similarly, if the second term is negative, then $\pi^{c r}-\pi^{n c r}$ is increasing in $\lambda$.

\section{A.2 Proof of Proposition 2}

The spread between expected profits of the venture capital contract and the bank contract can be written as:

$$
\begin{gathered}
\pi^{V C}-\max \left\{\pi^{n c r}, \pi^{c r}\right\} \\
=\min \left\{\pi^{V C}-\pi^{n c r}, \pi^{V C}-\pi^{c r}\right\} \\
=\min \left\{(1-\lambda)(1-\eta)\left(1-p_{l} R+\varpi\right)-(1-\lambda) c+\max \left\{\max \left\{\gamma I_{R \& D}, \varpi\right\}-c, 0\right\},\right. \\
\left.\eta(1-\lambda)\left(1-\frac{\varpi}{\gamma}\right)\left(p_{h} R-1\right)-(1-\lambda) c+\max \left\{\max \left\{\gamma I_{R \& D}, \varpi\right\}-c, 0\right\}\right\}
\end{gathered}
$$

The first part of the proposition is simply a sufficient condition for this term to be positive. And given that $\min \{$,$\} is a linear operator, for the rest of the$ proposition, all I need to do is separately prove that

$$
\begin{aligned}
& \pi^{V C}-\pi^{n c r} \\
& =(1-\lambda)(1-\eta)\left(1-p_{l} R+\varpi\right)-(1-\lambda) c+\max \left\{\max \left\{\gamma I_{\mathrm{R} \& \mathrm{D}}, \varpi\right\}-c, 0\right\}
\end{aligned}
$$

and

$$
\begin{aligned}
& \pi^{V C}-\pi^{c r} \\
& =\eta(1-\lambda)\left(1-\frac{\varpi}{\gamma}\right)\left(p_{h} R-1\right)-(1-\lambda) c+\max \left\{\max \left\{\gamma I_{\mathrm{R} \& \mathrm{D}}, \varpi\right\}-c, 0\right\}
\end{aligned}
$$

are both

1. decreasing in $\lambda$;

2. increasing in the spread of uncertainty $\Delta p$ while keeping $\hat{p}$ constant;

3. increasing in $I_{\mathrm{R} \& \mathrm{D}}$; and

4. increasing in $\gamma$.

1. Positive if $c<\min \left\{1-\eta\left(1-p_{l} R+\varpi\right), \eta\left(1-\frac{\varpi}{\gamma}\right)\left(p_{h} R-1\right)\right\}$ :

Given that $\max \left\{\max \left\{\gamma I_{R \& D}, \varpi\right\}-c, 0\right\}$ is guaranteed to be non-negative, then

$$
\min \left\{(1-\lambda)(1-\eta)\left(1-p_{l} R+\varpi\right)-(1-\lambda) c, \eta(1-\lambda)\left(1-\frac{\varpi}{\gamma}\right)\left(p_{h} R-1\right)-(1-\lambda) c\right\}>0
$$


is a sufficient condition for the spread to be positive. Dividing both sides by $(1-\lambda)$, and then adding $c$ on both sides, we have:

$$
\min \left\{1-\eta\left(1-p_{l} R+\varpi\right), \eta\left(1-\frac{\varpi}{\gamma}\right)\left(p_{h} R-1\right)\right\}>c
$$

2. Decreasing in $\lambda$ :

Both eqs [21] and [20] are linearly dependent on $\lambda$, and we also know that $(1-\lambda)$ is decreasing in $\lambda$, and that both $(1-\eta)\left(1-p_{l} R+\varpi\right)$ and $\eta\left(1-\frac{w}{\gamma}\right)\left(p_{h} R-1\right)$ are positive. Then it is clear that eqs [21] and [20] are both decreasing in $\lambda$.

3. Increasing in the spread of uncertainty $\Delta p$ while keeping $\hat{p}$ constant:

I will separately prove that $\pi^{V C}-\pi^{n c r}$ and $\pi^{V C}-\pi^{c r}$ are increasing when: first, when increasing $p_{h}$ and lowering $\eta$ while keeping $\hat{p}$ and $p_{l}$ constant; second, when lowering $p_{l}$ and increasing $\eta$ while holding $\hat{p}$ and $p_{h}$ constant; and third, when lowering $p_{l}$ and increasing $p_{h}$ while holding $\hat{p}$ and $\eta$ constant. Any other way of increasing the spread of uncertainty $\Delta p$ would just be a linear combination of these two types of changes.

(a) From eq. [20], we know that $\pi^{V C}-\pi^{n c r}$ is decreasing in $\eta$ when $p_{l}$ and $\hat{P}$ are held constant, because $(1-\eta)$ is decreasing in $\eta$ and $(1-\lambda)\left(1-p_{l} R+\varpi\right)$ is positive.

For $\pi^{V C}-\pi^{c r}$, after I substitute eq. [19] into eq. [21], we have:

$\pi^{V C}-\pi^{c r}=(1-\lambda)\left(1-\frac{\varpi}{\gamma}\right)\left(\hat{p} R-p_{l} R-\eta\left(1-p_{l} R\right)\right)-(1-\lambda) c+\max \left\{\max \left\{\gamma I_{\mathrm{R} \& \mathrm{D}}, \varpi\right\}-c, 0\right\}$ Since the partial derivative $\frac{\partial\left(\pi^{V C}-\pi^{c r}\right)}{\partial \eta}=-\left(1-p_{l} R\right)$ is negative, eq. [21] also has to be decreasing in $\eta$ when $p_{l}$ and $\hat{P}$ are held constant.

(b) By replacing $p_{l}$ with $\frac{\hat{p}-\eta p_{h}}{1-\eta}$ in eq. [20], we have:

$\pi^{V C}-\pi^{n c r}=(1-\lambda)\left[1+\varpi-\hat{p} R+\eta\left(p_{h} R-1-\varpi\right)\right]-(1-\lambda) c+\max \left\{\max \left\{\gamma I_{R \& D}, \varpi\right\}-c, 0\right\}$

The above term is increasing in $\eta$ when $\hat{p}$ and $p_{h}$ are both held constant, because $(1-\lambda)\left(p_{h} R-1-\varpi\right)$ is positive by assumption.

$\pi^{V C}-\pi^{c r}$ is linearly dependent on $\eta$, which is clearly increasing in $\eta$ when $p_{h}$ is held constant.

(c) Taken from eq. [20], the partial derivative $\frac{\partial\left(\pi^{V C}-\pi^{n c r}\right)}{\partial p_{l}}=-(1-\lambda)(1-\eta) R$ is negative, which means that $\pi^{V C}-\pi^{n c r}$ is decreasing in $p_{l}$ while $\eta$ is held constant.

Similarly, taken from eq. [21], the partial derivative $\frac{\partial\left(\pi^{V C}-\pi^{c r}\right)}{\partial p_{l}}=\eta(1-\lambda)\left(1-\frac{\varpi}{\gamma}\right) R$ is positive; thus, $\pi^{V C}-\pi^{c r}$ is increasing in $p_{h}$ while $\eta$ is held constant. 
4. Increasing in $I_{\mathrm{R} \& \mathrm{D}}$ :

Both $\pi^{V C}-\pi^{n c r}$ and $\pi^{V C}-\pi^{c r}$ are increasing in $I_{\mathrm{R} \& \mathrm{D}}$, because $\max \left\{\max \left\{\gamma I_{\mathrm{R} \& \mathrm{D}}, \varpi\right\}-c, 0\right\}$ is increasing in $I_{\mathrm{R} \& \mathrm{D}}$.

5. Increasing in $\gamma$ :

$\pi^{V C}-\pi^{n c r}$ is increasing in $\gamma$ since $\max \left\{\max \left\{\gamma I_{\mathrm{R} \& \mathrm{D}}, \varpi\right\}-c, 0\right\}$ is increasing in $\gamma$. On the other hand, because $\left(1-\frac{w}{\gamma}\right)$ is increasing in $\gamma$ and $\eta(1-\lambda)\left(p_{h} R-1\right)$ is positive, thus $\pi^{V C}-\pi^{c r}$ is also increasing in $\gamma$.

\section{References}

Bascha, A., and U. Walz. 2001. "Convertible Securities and Optimal Exit Decisions in Venture Capital Finance." Journal of Corporate Finance 7:285-306.

Baygan, G. 2003a. "Venture Capital Policy Review: Norway”, OECD Science, Technology and Industry Working Papers, No. 2003/17, OECD Publishing.

Baygan, G. 2003b. “Venture Capital Policy Review: United Kingdom”, OECD Science, Technology and Industry Working Papers, No. 2003/01, OECD Publishing.

Baygan, G., and M. Freudenberg. 2000. "The Internationalisation of Venture Capital Activity in OECD Countries: Implications for Measurement and Policy”, OECD Science, Technology and Industry Working Papers, No. 2000/07, OECD Publishing.

Berglöf, E. 1994. “A Control Theory of Venture Capital Finance.” Journal of Law, Economics, and Organization 10:247-267.

Black, B., and R. Gilson. 1998. "Venture Capital and the Structure of Capital Markets: Banks Versus Stock Markets." Journal of Financial Economics 47:243-277.

Bottazzi, L., M. Da Rin, and T. Hellmann. 2008. "Who Are the Active Investors?: Evidence From Venture Capital." Journal of Financial Economics 89:488-512.

Canada's Venture Capital and Private Equity Association. 2006. "2005 Annual Statistical Review."

Carpenter, R., and B. Petersen. 2002. "Capital Market Imperfections, High-Tech Investment, and New Equity Financing.” The Economic Journal 112:54-72.

Cornelli, F., and O. Yosha. 2003. "Stage Financing and the Role of Convertible Securities." Review of Economic Studies 70:1-32.

European Venture Capital Association and Others. 2006. "Evca Yearbook-2005 Annual Survey."

Gompers, P., and J. Lerner. 2004. The Venture Capital Cycle. Cambridge, MA: The MIT Press.

Groupe Secor Inc. 1998. "Financing Knowledge-based Small Business." The Task Force on the Future of the Canadian Financial Services Sector.

Hall, B. H. 2002. "The Financing of Research and Development." Oxford Review of Economic Policy 18:35-51.

Himmelberg, C. P., and B. C. Petersen. 1994. "R\&D and Internal Finance: A Panel Study of Small Firms in High-Tech Industries." The Review of Economics and Statistics 76:38-51.

Holmstrom, B., and J. Tirole. 1997. "Financial Intermediation, Loanable Funds, and the Real Sector.” Quarterly Journal of Economics 112:663-691. 
Hsu, D. H. 2004. “What Do Entrepreneurs Pay for Venture Capital Affiliation?” The Journal of Finance 59:1805-1844.

Kaplan, S., and P. Strömberg. 2003. "Financial Contracting Theory Meets the Real World: An Empirical Analysis of Venture Capital Contracts." Review of Economic Studies 70:281-315.

Krainer, J. 2000. "The Separation of Banking and Commerce." Federal Reserve Bank of San Francisco Economic Review 15-25.

National Venture Capital Association. 2006. "Nvca Vanture Capital Yearbook 2005."

Schmidt, K. 2003. "Convertible Securities and Venture Capital Finance." The Journal of Finance 58:1139-1166.

Schwienbacher, A. 2008. "Venture Capital Investment Practices in Europe and the United States." Financial Markets and Portfolio Management 22:195-217.

Tejada, R. 2003. "Venture Capital Policy Review: Spain”, OECD Science, Technology and Industry Working Papers, No. 2003/18, OECD Publishing.

Tyabjj, H., and V. Sathe. 2011. "Venture Capital Firms in Europe vs. America: The Under Performers." Ivey Business Journal. April-March.

Ueda, M. 2004. "Banks Versus Venture Capital: Project Evaluation, Screening, and Expropriation." The Journal of Finance 59:601-621. 